\title{
Inferior vena cava thrombosis during extracorporeal membrane oxygenation: a case report and review of the literature
}

\author{
YouLian Chen*, HuaiSheng Chen, XueYan Liu*, ChengYing Hong and HuaDong Zhang
}

\begin{abstract}
Background: Extracorporeal membrane oxygenation (ECMO) is an effective cardiopulmonary support therapy, which can provide temporary cardiopulmonary support for critically ill patients whose condition cannot be reversed by conventional therapy. However, there are many complications in the use of ECMO, such as bleeding, thrombosis, and so on. Among them, inferior vena cava (IVC) thrombosis which can cause pulmonary embolism is a rare complication, which may be life-threatening.

Case presentation: A 75-year-old female patient (Han Chinese ethnicity) with acute heart failure due to acute myocardial infarction in our department was retrospectively analyzed. After regular treatment was unsuccessful, she was treated with venoarterial ECMO (VA-ECMO). After her condition improved, she was withdrawn from ECMO and experienced a complication of IVC thrombosis. Enoxaparin was given immediately for $1 \mathrm{mg} / \mathrm{kg}$ every 12 hours hypodermic injection. The thrombus disappeared after anticoagulant therapy. She was discharged on the 60th day. Her level of consciousness returned to normal without residual central nervous system-related complications.

Conclusions: IVC thrombosis is one of the possible serious complications in the process of ECMO therapy. Prevention of thrombosis and optimization of the anticoagulant regimen are the main preventive measures. Anticoagulant therapy is still the main treatment of IVC thrombosis in the process of ECMO therapy. Other interventional strategies need to accumulate clinical experience.
\end{abstract}

Keywords: Extracorporeal membrane oxygenation, Inferior vena cava thrombosis, Acute respiratory distress syndrome, Cardiogenic shock

\section{Background}

Extracorporeal membrane oxygenation (ECMO) is an effective cardiopulmonary support therapy, which can provide temporary cardiopulmonary support for critically ill patients, help improve hypoxia, buy more time for the treatment of primary diseases, and save many

\footnotetext{
*Correspondence: 381904698@qq.com; 944753897@qq.com
} Present Address: Department of Critical Care Medicine, Shenzhen People's Hospital, The Second Clinical Medical College of Jinan University, The First Affiliated Hospital of South University of Science and Technology, No.1017, Dong Men North Road, Luohu District, Shenzhen 518020, China dying patients whose condition cannot be reversed by conventional therapy [1].

However, there are many complications associated with the use of ECMO, such as acute kidney injury, bleeding, thrombosis, and so on [2]. Inferior vena cava (IVC) thrombosis is a rare complication, but pulmonary embolism caused by thrombus shedding may be life-threatening. There are few reports and no standardized consensus on prevention and treatment. This paper reports the diagnosis and treatment of a patient with IVC thrombosis during ECMO, and discusses the prevention and treatment of IVC thrombosis during ECMO through a original author(s) and the source, provide a link to the Creative Commons licence, and indicate if changes were made. The images or other third party material in this article are included in the article's Creative Commons licence, unless indicated otherwise in a credit line to the material. If material is not included in the article's Creative Commons licence and your intended use is not permitted by statutory regulation or exceeds the permitted use, you will need to obtain permission directly from the copyright holder. To view a copy of this licence, visit http://creativecommons.org/licenses/by/4.0/. The Creative Commons Public Domain Dedication waiver (http://creativeco mmons.org/publicdomain/zero/1.0/) applies to the data made available in this article, unless otherwise stated in a credit line to the data. 
literature review. Informed consent was obtained for all special treatment protocols involved.

\section{Case presentation}

A 75-year-old female patient (Han Chinese ethnicity) weighing $55 \mathrm{~kg}$ with cardiogenic shock was admitted to our critical care department. After regular treatment was unsuccessful, she was treated with venoarterial extracorporeal membrane oxygenation (VA-ECMO) on January 19, 2021, for acute myocardial infarction complicated by cardiogenic shock. MAQUET ECMO equipment was used. The ECMO catheter was implanted into the right femoral vein and left femoral artery under ultrasound guidance. The end of the catheter was confirmed to the level of the right atrium by ultrasound. VA-ECMO was established with a rotational speed of $3500 /$ minute, flow rate of $3.2 \mathrm{~L} /$ minute, fraction of inspired oxygen $\left[\mathrm{FiO}_{2}\right]$ of $100 \%$, gas flow rate of $4 \mathrm{~L} /$ minute, and vasoactive drugs dobutamine $6 \mu \mathrm{g} /(\mathrm{kg} /$ minute) and norepinephrine 0.1 $\mu \mathrm{g} /(\mathrm{kg} /$ minute $)$ The parameters of the ventilator were adjusted as follows: oxygen concentration $50 \%$, respiratory rate 10 times $/$ minute, tidal volume $5 \mathrm{~mL} / \mathrm{kg}$, and positive end-expiratory pressure $8 \mathrm{cmH}_{2} \mathrm{O}$. When ECMO was established, due to abnormal coagulation function (activated clotting time $[\mathrm{ACT}]>200$ seconds, activated partial thromboplastin time [APTT] $>160$ seconds), anticoagulation was temporarily delayed. A total of 600 $\mathrm{mL}$ of plasma and $4 \mathrm{U}$ of red blood cell suspension were supplemented. ACT was monitored every 2 hours. When ACT decreased to less than 200 seconds, heparin anticoagulation was started at APTT of 60 seconds (Fig. 1). We conducted a physical examination at the bedside, and we found that the pupil size of the patient's eyes were not equal, so we performed a computed tomography (CT) examination. The CT report showed cerebral infarction and possibly a small amount of bleeding after infarction in the right parietal lobe. The right frontal

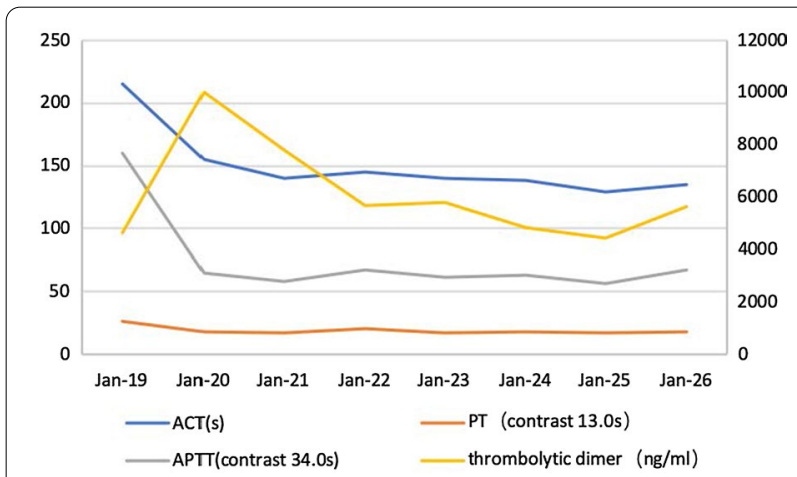

Fig. 1 Monitoring values of anticoagulant dosage and coagulation function during extracorporeal membrane oxygenation lobe showed basal ganglia cavity infarction and elderly brain changes (Fig. 2). Because of the risk of intracerebral hemorrhage, we used a low-intensity heparin anticoagulation strategy. With the assistance of ECMO, the patient underwent coronary angiography + percutaneous coronary angioplasty + stent implantation aided by digital subtraction angiography (DSA) on January 20 at 08:20-09:35. After the operation, the cardiac function gradually recovered and the hemodynamics improved. On January 21, dopamine was stopped, and low-dose norepinephrine combined with dobutamine was continued. Because of the progressive decrease in platelets and the low activity of antithrombin III, the anticoagulation efficiency of unfractionated heparin was considered to decrease, and heparin-induced thrombocytopenia was not excluded. Argatroban anticoagulation was used to maintain APTT of between 50 and 70 seconds. On January 26, ECMO parameters were adjusted to a rotation speed of $2795 \mathrm{r} /$ minute, blood flow $1.61 \mathrm{~L} /$ minute, $\mathrm{FiO}_{2} \%$ $21 \%$, air flow $1.5 \mathrm{~L} /$ minute, and mean arterial pressure (MAP) $90 \mathrm{mmHg}$. Bedside echocardiography showed that the patient's cardiac systolic function was improved, left ventricular ejection fraction (LVEF) (biplane Simpson method) was $35 \%$, and hemodynamics were stable. As the patient's cardiac function improved, we discussed with caregivers and family about the discontinuation of ECMO therapy, and the ECMO was removed after evaluation. On January 27, 2021, color Doppler ultrasound showed 34\% LVEF (biplane Simpson method) and thrombosis from the IVC to the atrium (about $70 \mathrm{~mm}$ in length, $8 \mathrm{~mm}$ in width, with a floating tail end, Fig. 3a). Enoxaparin was given immediately for $1 \mathrm{mg} / \mathrm{kg}$ every 12 hours ih. On February 5, 2021, color Doppler echocardiography showed thrombosis from the IVC to the right

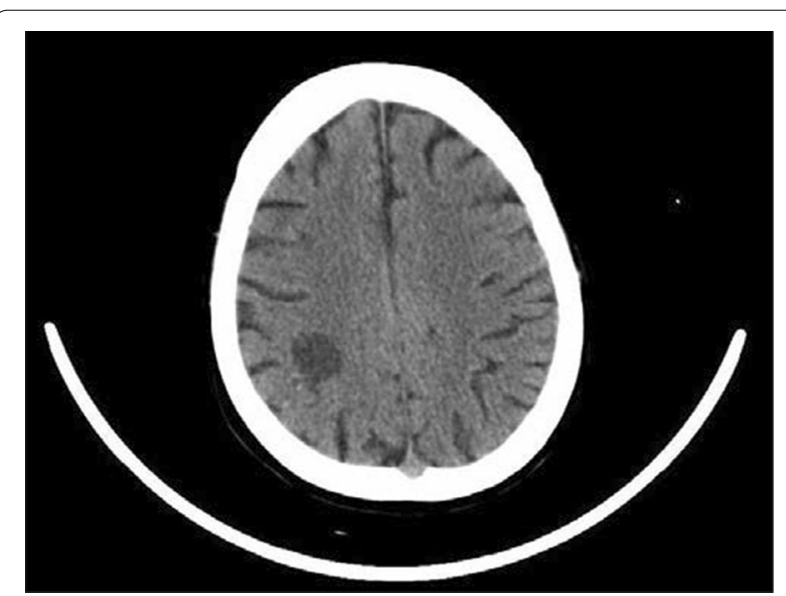

Fig. 2 In the right parietal lobe, cerebral infarction and bleeding after a small amount of cerebral infarction may be possible 


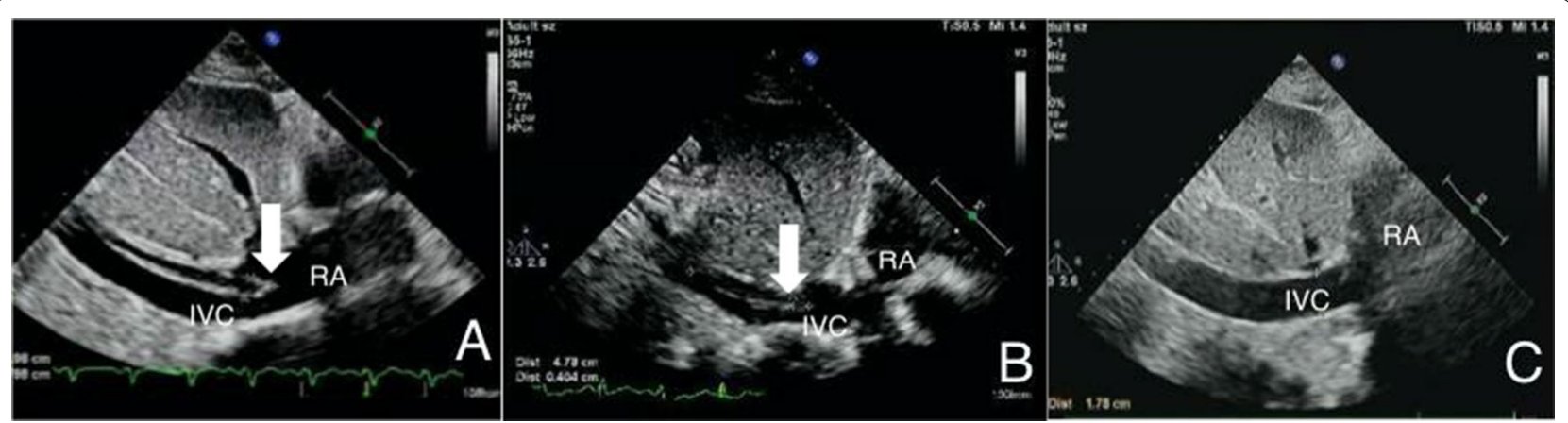

Fig. 3 Echocardiography after cannula removal. a shows that after extracorporeal membrane oxygenation catheter removal, the inferior vena cava thrombosis was found by ultrasonography. $\mathbf{b}$ shows that the thrombosis of the inferior vena cava decreases gradually after heparin anticoagulation. c shows that the thrombus of inferior vena cava disappeared after heparin anticoagulation. RA right atrium, IVC inferior vena cava, Thrombosis in inferior vena cava (arrowhead)

atrium entrance (compared with January 27, 2021, volume reduced, shape changed, length about $48 \mathrm{~mm}$, width about $4 \mathrm{~mm}$, tail end floating, Fig. 3b). On February 19, 2021, color Doppler echocardiography showed no obvious abnormal echo in the IVC; combined with medical history, thrombus disappeared after anticoagulant therapy (Fig. 3c). Later, the patient's condition gradually stabilized. On the 30th day, she was taken off the ventilator and administered oral rivaroxaban instead of anticoagulants. Due to decreased muscle strength of her limbs, she received rehabilitation exercise and was discharged on the 60th day. Her level of consciousness returned to normal without residual central nervous system-related complications.

\section{Discussion}

Although ECMO may be the most effective treatment for patients with severe heart or respiratory failure, it has many complications, including bleeding (33\%), hemolysis $(18 \%)$, and venous microthrombosis (10\%) [3]. During ECMO, there are many risk factors for thrombosis, including disease severity, sedation, frequent blood transfusion, non-pulse blood flow, and blood exposure to a non-biological ECMO pipeline, all of which are the microenvironment leading to thrombosis, so anticoagulation therapy must be considered [4]. However, the incidence of bleeding during ECMO can be as high as 29\%, with $10 \%$ at risk of massive bleeding and $4-10 \%$ at risk of intracranial hemorrhage. This group of patients may have insufficient anticoagulation due to the existence of bleeding risk factors, which is also an important reason for thrombosis [5]. Because of the possible risk of cerebral hemorrhage in our case, we reduced the anticoagulation intensity of heparin, which eventually led to IVC thrombosis.
In the process of ECMO treatment, we often encounter distal limb thrombosis. The treatment measures include strengthening anticoagulation, replacing the catheter, removing the thrombus, and other treatment measures, which are relatively easy to handle and of relatively low risk [6]. However, the incidence of thrombus formation near the entrance of the IVC is low, and thrombus shedding leads to acute massive pulmonary embolism, and even sudden death, which is rarely reported.

We retrospectively analyzed patients with IVC thrombosis during ECMO therapy reported in the previous literature. The PubMed database was searched by using the keywords "inferior vena cava thrombosis" and "extracorporeal membrane oxygenation." Our search showed 13 other reports on the subject (Table 1) [7-18]. Among the 14 patients, five patients were treated with VA-ECMO, mainly cardiogenic shock patients, including one heart transplant patient; the other eight patients were treated with veno-venous ECMO (VV-ECMO) after acute respiratory failure, including two lung transplant patients. Unfortunately, these two patients eventually died. The cause of death was not caused by pulmonary embolism, which may be related to the severity of the disease. According to the literature, the causes of IVC thrombosis are as follows: blood loss, insufficient volume, decreased blood flow velocity [14], continuous catheter shaking, low-intensity anticoagulation, or no heparin anticoagulation, all of which are also important reasons for thrombosis on the surface of ECMO catheter. In addition, because there is no heparin coating on the outer surface of the ECMO catheter, thrombosis is more likely to occur. If the antithrombin III (ATIII) level is low, there is also a risk of thrombosis; when the ATIII $<60 \%$ (normal range $80-120 \%)$. The anticoagulant efficiency of heparin decreased, and conventional ACT or APTT could not 
Table 1 Case reports of inferior vena cava thrombosis during extracorporeal membrane oxygenation

\begin{tabular}{|c|c|c|c|c|c|c|c|}
\hline Year & Author & Thrombus site & Cause & Modality of ECMO & Intervention & Complication & Outcome \\
\hline 1997 & Riccabona et al. [7] & IVC & Heart failure & VA-ECMO & Anticoagulation & No & Survival \\
\hline 2002 & Jack et al. [8] & IVC & Lung transplantation & W-ECMO & None & No & Death \\
\hline 2006 & Bruno Mégarbane et al. [9] & IVC & Cardiogenic shock & VA-ECMO & Anticoagulation & No & Survival \\
\hline 2010 & Alicia Sievert et al. [10] & IVC & ARDS & W-ECMO & Anticoagulation & No & Survival \\
\hline 2011 & Sylvain Beurtheret et al. [11] & IVC & Respiratory failure & VV-ECMO & Anticoagulation & PE & Survival \\
\hline 2015 & Philippe Morimont et al. [12] & RA & Heart transplantation & VA-ECMO & Operation & No & Survival \\
\hline 2015 & Thomas Bein et al. [13] & IVC & ARDS & W-ECMO & Anticoagulation & No & Survival \\
\hline 2017 & Cristina Ruisanchez et al. [14] & IVC & ARDS & W-ECMO & Anticoagulation & No & Survival \\
\hline 2017 & Samantha Wills et al. [15] & IVC & ARDS & W-ECMO & Anticoagulation & No & Survival \\
\hline 2018 & Magdy et al. [16] & IVC & Respiratory failure & W-ECMO & Operation & No & Survival \\
\hline 2020 & Marin Pavlov et al. [17] & IVC & Cardiogenic shock & VA-ECMO & Anticoagulation & No & Survival \\
\hline 2021 & Ting Chen et al. [18] & IVC & Lung transplantation & W-ECMO & Anticoagulation & No & Death \\
\hline
\end{tabular}

$E C M O$ extracorporeal membrane oxygenation, $V A$ venoarterial, $V V$ veno-venous, $A R D S$ acute respiratory distress syndrome, IVC inferior vena cava, $P E$ pulmonary embolism, $R A$ right atrium

accurately determine the anticoagulant intensity, leading to thrombosis [10].

The clinical manifestations of IVC thrombosis in ECMO patients were nonspecific, mainly manifested as "IVC syndrome," and distal limb edema in some patients after removal of the ECMO catheter [13]. In addition, if IVC thrombosis occurs during ECMO, sudden hypoxemia and ECMO flow decrease may also be caused by the patient's postural changes [14]. Hemolysis has also been reported [15].

The main diagnostic methods were ultrasound examination of the heart and IVC $[7,16]$. It is worth noting that there is a kind of thrombus formed outside the ECMO catheter, which is not easy to find during ECMO, because it can be easily mistaken for the ECMO catheter wall. After the ECMO catheter was removed, two-dimensional ultrasound showed that the thrombus became tubular; color Doppler ultrasound showed that the blood flow could pass through the thrombus, and even the tail of the thrombus could float, as shown in the ultrasound in our case (Fig. 3a) [17, 18]. At present, there is no good method to identify this kind of thrombus, which may be judged by repeatedly measuring the wall thickness of the ECMO catheter. Therefore, color Doppler ultrasound can provide a suitable method for the detection and followup of venous thrombosis during ECMO or after removal of the ECMO catheter to prevent the occurrence of serious sequelae, such as pulmonary embolism.

Treatment measures include drug therapy, vascular interventional therapy, and surgery. According to a literature analysis, $76.9 \%(10 / 13)$ of patients received anticoagulant therapy, and there is no report about thrombolysis at present. One patient undergoing thrombectomy was a heart transplant patient, and another had received lung transplantation, and their prognosis was good. Both of the deaths were lung transplant patients $[8,18]$. This indicates that the severity of the disease is an important factor affecting patient survival. At present, there is no report on the application of vascular interventional therapy. However, it has been reported that the AngioVac System can successfully evacuate the thrombus in cases of ECMO-related thrombosis [19].

\section{Conclusions}

Based on our clinical cases and literature analysis, we believe that IVC thrombosis is one of the serious complications associated with the process of ECMO therapy. Once it occurs, it is closely related to the mortality and disability rate of patients. Prevention of thrombosis and optimization of the anticoagulant regimen are the main preventive measures, and anticoagulant therapy is still the main cause of IVC thrombosis in the process of ECMO therapy. Other interventional strategies need to accumulate clinical experience.

\section{Acknowledgements}

We thank Dr. Lixin Chen for her help in ultrasonic examination; we are grateful to Dr. Chenxi Li, Dr. Xi Wang, Dr. Zhenmi Liu, and Dr. Zewei Huang for supplying us additional data. We also acknowledge the time that Dr. Zhiqiang Zhou and Dr. Shunkang Wen took to respond to our queries.

\section{Authors' contributions}

XYL designed the study. HSC wrote the draft. CYH collected the data. HDZ analyzed the data. YLC performed the data analyses and wrote the manuscript. XYL approved the final manuscript. All authors read and approved the final manuscript.

\section{Funding}

The study was supported by the Shenzhen Key Laboratory of Prevention and Treatment of Severe Infections (Grant No. ZDSYS20200811142804014) and the Shenzhen Key Medical Discipline Construction Fund (Grant No. SZXK045). 
Availability of data and materials

Not applicable.

\section{Declarations}

\section{Ethics approval and consent to participate}

We received approval by the Board of Ethics at Shenzhen People's Hospital.

\section{Consent for publication}

Written informed consent was obtained from the patient for publication of this case report and any accompanying images. A copy of the written consent is available for review by the Editor-in-Chief of this journal.

\section{Competing interests}

The authors declare that they have no competing interests.

Received: 8 May 2021 Accepted: 11 August 2021

Published online: 18 October 2021

\section{References}

1. Marasco SF, Lukas G, McDonald M, et al. Review of ECMO (extra corporeal membrane oxygenation) support in critically ill adult patients. Heart Lung Circ. 2008;17(Suppl 4):41-7.

2. Marasco SF, Lukas G, McDonald M, et al. Incremental effect of complications on mortality and hospital costs in adult ECMO patients. Perfusion. 2021. https://doi.org/10.1177/02676591211005697.

3. Zangrillo A, Landoni G, Biondi-Zoccai G, et al. A meta-analysis of complications and mortality of extra-corporeal membrane oxygenation. Crit Care Resusc. 2013;15(3):172-8.

4. Doyle AJ, Hunt BJ. Current understanding of how extracorporeal membrane oxygenators activate haemostasis and other blood components. Front Med (Lausanne). 2018;5:352.

5. Vaquer S, de Haro C, Peruga P, Oliva JC, Artigas A. Systematic review and meta-analysis of complications and mortality of veno-venous extracorporeal membrane oxygenation for refractory acute respiratory distress syndrome. Ann Intensive Care. 2017;7:51.

6. Menaker J, Tabatabai A, Rector R, et al. Incidence of cannula-associated deep vein thrombosis after veno-venous extracorporeal membrane oxygenation. ASAIO J. 2017;63:588-91.

7. Riccabona M, Kuttnig-Haim M, Urlesberger B, et al. Venous thrombosis in and after extracorporeal membrane oxygenation: detection and followup by color Doppler sonography. Eur Radiol. 1997;7(9):1383-6.
8. Bui JD, Despotis GD, Trulock EP, et al. Fatal thrombosis after administration of activated prothrombin complex concentrates in a patient supported by extracorporeal membrane oxygenation who had received activated recombinant factor VII. J Thorac Cardiovasc Surg. 2002;124:852-4.

9. Mégarbane B, Leprince P, Guerrier G, et al. Extracorporeal life support in a case of acute carbamazepine poisoning with life-threatening refractory myocardial failure. Intensive Care Med. 2006;32:1409-13.

10. Sievert A, Uber W, Laws S, et al. Improvement in long-term ECMO by detailed monitoring of anticoagulation: a case report. Perfusion. 2011;26(1):59-64

11. Beurtheret S, Mastroianni C, Pozzi M, et al. Extracorporeal membrane oxygenation for 2009 influenza A (H1N1) acute respiratory distress syndrome: single-centre experience with 1-year follow-up. Eur J Cardiothorac Surg. 2012;41(3):691-5

12. Morimont $P$, Lambermont $B$, Gaspard $V$, et al. Molding thrombus of an ECMO cannula floating in the right atrium. Intensive Care Med. 2015;41(11):1965-6.

13. Bein T, Philipp A, Pregler B, et al. Long-segment caval thrombus after removal of ECMO cannula. Intensive Care Med. 2015;41(11):1967-8.

14. Ruisanchez C, Sarralde JA, Gonzalez-Fernandez C, et al. Sudden dysfunction of veno-venous extracorporeal membrane oxygenation caused by intermittent cannula obstruction: the key role of echocardiography. Intensive Care Med. 2017;43(7):1055-6.

15. Wills $S$, Forrest $P$, et al. Inferior vena cava thrombosis as a cause of haemolysis in a patient on ECMO. Perfusion. 2017;32(2):168-70.

16. El-Sayed Ahmed MM, Renew JR, Rodrigues E, et al. TEE-guided transatrial inferior vena cava and hepatic veins thrombectomy during double lung transplantation in a W ECMO-supported patient. J Card Surg. 2018:33(12):870-1.

17. Pavlov M, Babić Z, Bulj N, et al. Unusual pattern of inferior vena cava thrombosis after veno-arterial extracorporeal membrane oxygenation: a report of two cases. Croat Med J. 2020;61(6):555-60.

18. Chen T, Yao L, Fan X, Zhu C, et al. Massive hollow catheter thrombus in venovenous extracorporeal membrane oxygenation assisted lung transplantation. Medicine (Baltimore). 2021;100(1):e24235.

19. Griffith KE, Jenkins E, Copenhaver W, et al. Novel use of the AngioVac ${ }^{\circledR}$ system to remove thrombus during simultaneous extracorporeal membrane oxygenation life support. Perfusion. 2016;31:164-8.

\section{Publisher's Note}

Springer Nature remains neutral with regard to jurisdictional claims in published maps and institutional affiliations.
Ready to submit your research? Choose BMC and benefit from:

- fast, convenient online submission

- thorough peer review by experienced researchers in your field

- rapid publication on acceptance

- support for research data, including large and complex data types

- gold Open Access which fosters wider collaboration and increased citations

- maximum visibility for your research: over 100M website views per year

At $\mathrm{BMC}$, research is always in progress.

Learn more biomedcentral.com/submissions 